\title{
Análise de uma Cidade Policêntrica: o Caso de Resende-RJ, no Médio Vale do Paraíba
}

\author{
Analysis of a Polycentric City: \\ the Case of Resende in the Middle Paraíba Valley
}

\author{
Monique Deise Guimarães Bastos ${ }^{i}$ \\ Universidade Federal do Rio de Janeiro \\ Rio de Janeiro, Brasil
}

Resumo: A reestruturação produtiva, vinculada ao período pós-fordista dos anos 1970, redefiniu a organização espaço-temporal do trabalho e fez repercutir em algumas cidades os rebatimentos espaciais de sua dinâmica. Esse é o caso de Resende, localizada no Médio Vale do Paraíba/RJ, que teve boa parte de sua organização interna alterada em consequência da entrada e fixação na cidade de diversas indústrias, algumas delas multinacionais, que redefiniram sua dinâmica econômica. Assim, sob a perspectiva do processo espacial de descentralização e emergência do primeiro subcentro de comércio e serviços da cidade, o presente trabalho tem por objetivo apresentar um dos efeitos urbanos desse novo papel econômico-produtivo de Resende. Além disso, o artigo se propõe a oferecer possibilidades de diagnóstico e ferramentas metodológicas que ajudem na análise da produção de uma cidade policêntrica.

Palavras-chave: Reestruturação Produtiva; Reestruturação Urbana; Cidades Médias.

\begin{abstract}
Restructuring of production related to global post-Fordism after 1970 has redefined the space-time organization of work and its effects are evident in cities like Resende located in the Middle Paraíba Valley of Rio de Janeiro State. The internal organization of this city changed with the establishment of a number of new industries by important national and multinational corporations, which redefined local economic dynamics. Through the analysis of spatial decentralization and the rise of the first commercial and service sub-center within the city, this study has the aim of presenting how the new economic and productive role of Resende has affected urban space. In addition, the article offers methodological tools and criteria for evaluation for the analysis of production in polycentric cities.
\end{abstract}

Keywords: Productive Restructuring; Urban Restructuring; Medium-Sized Cities.

\footnotetext{
' Mestranda do Programa de Pós-Graduação em Geografia. Graduada em Licenciatura em Geografia pela UFRJ. Pesquisadora colaboradora do Grupo de Pesquisa sobre Reestruturação Urbana e Centralidade (GRUCE). moniquebastos.ufrj@gmail.com
} 


\section{Introdução}

A dinâmica de reestruturação urbana está ligada à atuação de inúmeros processos e agentes, que redefinem ao longo de eras a organização convencional da cidade. Promovendo em seus espaços a combinação entre mudança e continuidade, as reestruturações urbana e da cidade comportam a sobreposição entre os novos elementos de sua composição e os resíduos de uma estrutura anterior. Dentro dessa tensão entre passado e presente, essa dinâmica passou a ser orientada por uma nova ordem produtiva, ascendida na década de 1970 e inspirada pelo então novo modelo de acumulação flexível, que começava a vigorar em boa parte do mundo a partir desse momento.

Também denominado de pós-fordismo, esse novo modo produtivo reorganizou o espaço econômico mundial, promovendo algumas cidades a espaços especiais para sua reprodução. Tal é o caso das cidades médias, que - à medida que atenderam aos novos requisitos condicionados pela lógica da reestruturação produtiva -, por consequência, também assistiram a um dinâmico movimento de reestruturação urbana, que redefiniu muitos de seus processos e formas espaciais. É nesse sentindo que a cidade média de Resende/RJ (localizada Médio Vale do Paraíba) serve de objeto empírico desta análise, já que, a partir da década de 1990, insere-se nos circuitos econômicos mundiais, atraindo um número importante de indústrias estrangeiras.

No decorrer dessa década, passa a ser notória a reorganização interna da cidade, aqui verificada especialmente sob a luz do processo espacial de descentralização urbana. Por meio dela, pôde ser verificada de modo visível e metodológico a emergência do seu primeiro subcentro de comércio e serviços - localizado em um dos seus bairros, o Cidade Alegria -, processo entendido como um dos reflexos da mudança do perfil econômico de Resende/RJ, associado à participação do município nos circuitos produtivos mundiais. Estes alteraram o nível de complexidade das relações econômicas da cidade e, por consequência, de suas dinâmicas espaciais nas escalas intra e interurbana.

É por esse motivo que o debate aqui proposto tem por finalidade apresentar o caso de Resende/RJ como um modelo de espaço tanto reprodutor da nova tendência produtiva atual, quanto alterado espacialmente pelo exercício de sua nova função econômica. Assim, pretende-se, no decorrer deste trabalho, demonstrar a reorganização recente do espaço urbano de Resende/RJ a partir da emergência do processo espacial da descentralização que a promoveu a uma cidade policêntrica, cuja complexidade é entendida como um reflexo das novas funções produtivas e econômicas experimentadas por ela (SILVA, 2017a; SILVA, 2017b; SPOSITO e SILVA, 2017).

\section{Da Reestruturação Produtiva à Econômica, da Reestruturação Urbana à da Cidade}

Surgido quando "a antiga ordem está suficientemente esgarçada para impedir os remendos adaptativos convencionais", o processo de reestruturação, segundo Soja (SOJA, 1993, p. 193), mantém-se na relação entre manutenção e mudança de uma ordem vigente, sendo, portanto, mais do que só sinônimo de uma mera transformação. Dentro 
dessa perspectiva de complexidade, a dinâmica de reestruturação também pode orientar-se a partir de diversos processos, estando alguns deles relacionados entre si, como é o caso das reestruturações produtiva/econômica e urbana/da cidade.

No caso das transformações de cunho produtivo, estas se associam ao que é chamado de regime de acumulação flexível, que emerge de "um confronto direto com a rigidez do fordismo" (HARVEY, 2007, p. 140). Tal "modalidade" de reestruturação econômica tem como característica marcante o esforço de flexibilização dos diversos processos, segmentos e relações do trabalho produtivo, resultando, segundo o mesmo autor, no "surgimento de setores de produção inteiramente novos, novas maneiras de fornecimentos de serviços financeiros, novos mercados", além de uma intensificação no âmbito da "inovação comercial, tecnológica e organizacional".

Nesse sentido, a reestruturação produtiva, que acompanhou a consolidação do modelo de acumulação flexível, surge com o potencial de reorientar fluxos econômicos e inserir novos espaços em suas redes. Partindo da nova prerrogativa de flexibilidade, as cidades passam a exercer novos papéis, o que contribui para a reorganização de toda a divisão do trabalho (MOREIRA, 2003). Consequentemente, são promovidas mudanças na estrutura econômica desses espaços. Como aponta Carvalho (2013, p. 100), este "rearranjo nas funções das cidades aconteceu devido à reestruturação que movimentou as estruturas produtivas no espaço", alterando a composição interna de suas características, que passaram "por um processo de adequação a uma nova realidade, na qual indústrias de diversos setores passaram a fixar-se no espaço e mudar toda a funcionalidade existente".

Esse é o caso de Resende/RJ, localizada no Médio Vale do Paraíba, que, ao lado de outras cidades da mesma categoria, passam a ter suas pequenas "diferenciações espaciais" exploradas (HARVEY, 2007, p. 265). Nela, percebe-se um modelo bastante perfeito de cidade no que tange à sua participação na reprodução da ordem produtiva vigente, na reestruturação de sua lógica econômica em decorrência disso e, por consequência, na reorganização de sua estrutura urbana a partir do surgimento de novas formas e funções espaciais. É como assinala Sposito (2007, p. 13):

[...] a instalação de "distritos industriais", que devem ser, mais propriamente, chamadas de áreas de localização industrial com diferenças entre o tamanho das empresas que têm capacidades diversas na incorporação de novas tecnologias, na participação na produção industrial ou nas diferentes formas de arrecadação oficial, contempla a complexidade da reestruturação das cidades médias no momento atual.

Já no que diz respeito ao debate sobre reestruturação urbana, é importante que algumas considerações conceituais sejam bem contornadas, e a compreensão sobre a escala de seus impactos espaciais é uma delas. Ao tornarem-se palco da reestruturação produtiva, as cidades médias testemunham mudanças em sua estrutura tanto em escala interna, da cidade, quanto na que extrapola seus limites político-administrativos, da sua escala regional, o que justifica a diferenciação conceitual entre os processos de reestruturação urbana e reestruturação da cidade. 
Assim esclarece Sposito (2007) ao considerar a reestruturação urbana sob a escala interurbana, regional - das redes urbanas -, e a reestruturação da cidade sob o recorte do interior da própria cidade. Dessa forma, sem preterir a evidente articulação entre ambas, já que "não há estruturação urbana sem estruturação da cidade e vice-versa" (SPOSITO, 2004, p. 312), esta pesquisa se concentra na compreensão da reestruturação de Resende/RJ sob a perspectiva escalar intraurbana da cidade média, ou seja, no entendimento da influência de sua reestruturação econômica - reflexo de sua refuncionalização produtiva -, e no aparecimento de novas formas e funções espaciais dentro dos limites da cidade.

\section{O Uso da Forma, da Função, da Estrutura e do Processo como Recursos de Análise}

Os conceitos de forma, função, estrutura e processo podem ser usados como categorias primárias na compreensão da atual organização espacial. Vistos em combinação, eles abrandam os efeitos da teorização de um único fator, que não leva em conta as características verdadeiras, inseparáveis e interatuantes do desenvolvimento espacial. (SANTOS, 1985, p. 38).

O objetivo de iniciar este novo capítulo com a citação supracitada é o de justificar o uso de algumas das principais ferramentas conceituais exploradas na operacionalização desta pesquisa. Em outras palavras, para demonstrar a reorganização do espaço urbano de Resende/RJ, o trabalho se baseia nas noções de forma, função, estrutura e processo como importantes recursos que sustentam sua análise, mas não de modo individualizado. Portanto, como propõem Santos e Lefebvre (1971 apud LENCIONI, 1988) ao explicarem que "não deve ser dada prioridade absoluta a nenhuma das noções de forma, função e estrutura" (LENCIONI, 1988, p. 2), a pesquisa visa ao uso articulado entre tais conceitos, acrescentando-se, inclusive, a noção de processo.

Desse modo, a começar por estrutura, Santos (1985, p. 38) apresenta o conceito a partir do seu diálogo com outro, o de forma, indicado pelo autor como "uma estrutura revelada", sendo "mais visível" e, "até certo ponto, mais fácil de analisar que a estrutura". Esta, por sua vez, "implica a inter-relação de todas as partes de um todo; o modo de organização ou construção" (p. 37), e é vista sob uma perspectiva mais visual que se baseia nas formas. Logo, entendendo a produção da forma espacial do que seria o primeiro subcentro de Resende/RJ, há aí um importante meio teórico de analisarmos e compreendermos o possível processo de descentralização urbana dessa cidade média.

Para a melhor compreensão dessa forma espacial, também foi utilizada a contribuição de Corrêa (1989) como orientação teórica deste trabalho. A partir dela, o subcentro aparece como associado à duas categorias de atividades, uma de natureza industrial e outra relacionada à estrutura comercial e de serviços. No caso desta pesquisa, o subcentro será entendido pela perspectiva da segunda classificação de atividades, sendo determinado, segundo o mesmo autor, pela densidade e pelo nível de renda da população. Além disso, os subcentros são considerados: 
[...] inseridos em contextos espaciais mais restritos e são formados, inicialmente por estabelecimentos de proprietários locais, visando atender a uma demanda local, gerada pelo consumo específico de uma população com características homogêneas, que difere da possível pluralidade socioeconômica dos frequentadores do Centro Principal. (SILVA, 2004, p. 64).

Tais qualificantes, como será mais bem apontado adiante, são importantes elementos para a identificação do possível subcentro na cidade média - no bairro Cidade Alegria -, que pode ser claramente caracterizado por atividades comerciais e de serviços, apresentando natureza muito semelhante à descrita por Silva (2004). Assim, a hipótese deste trabalho se justifica na possibilidade de que a reestruturação da cidade possa estar ocorrendo também pela via da produção de formas espaciais nesses moldes, consequência do novo papel produtivo e econômico desempenhado pela cidade média.

Em outras palavras, pressupõe-se que "[...] uma ação contínua, desenvolvendo-se em relação a um resultado qualquer, implicando conceitos de tempo (continuidade) e mudança [...]" (SANTOS, 1985, p. 37), tenha valorizado atrativos em outras áreas de Resende/RJ - como terras não ocupadas e baixo preço de impostos -, justificando o desenvolvimento de infraestrutura e facilidades de transporte (COLBY, 1930, apud CORRÊA, 1989) que fortaleceriam o processo espacial da descentralização, desenhando no espaço a forma urbana de um subcentro.

Ainda dentro do que foi discutido por Santos, a função, "tarefa ou atividade esperada" (p. 37) do possível subcentro de análise elevaria Resende/RJ à posição de cidade policêntrica, tornando-se mais complexa do ponto de vista de sua organização interna. Essa condição justifica, portanto, o desenvolvimento deste trabalho, que pretende apresentar, assim, as consequências espaciais da reorientação dos fluxos econômicos que circulam em seu espaço, decorrente da inserção da cidade média nos circuitos produtivos mundiais.

\section{Cidades médias, Médio Vale do Paraíba, Resende/RJ e Cidade Alegria}

Todas as questões apresentadas até aqui não só explicam, mas justificam uma análise mais apurada do papel de algumas cidades médias brasileiras, proeminentes na nova lógica produtiva em vigor. É nessa direção, e correspondendo às recentes normativas produtivas contemporâneas, que a cidade média de Resende/RJ será apresentada a fim de exemplificar a complexidade que nasce das relações entre diversas modalidades de reestruturações debatidas até aqui.

A microrregião do Médio Vale do Paraíba, da qual faz parte a cidade média, localizada na mesorregião do Sul Fluminense, é formada por 12 municípios (Figura 1). Apontado como um dos mais importantes polos industriais do Brasil, o Médio Vale justifica sua proeminência produtiva pela instalação de bases de empresas multinacionais, principalmente do seguimento automobilístico, como Volkswagen (1996), PSA Peugeot Citroën (2001), Hyundai (2013), Nissan (2014), dentre outras. 


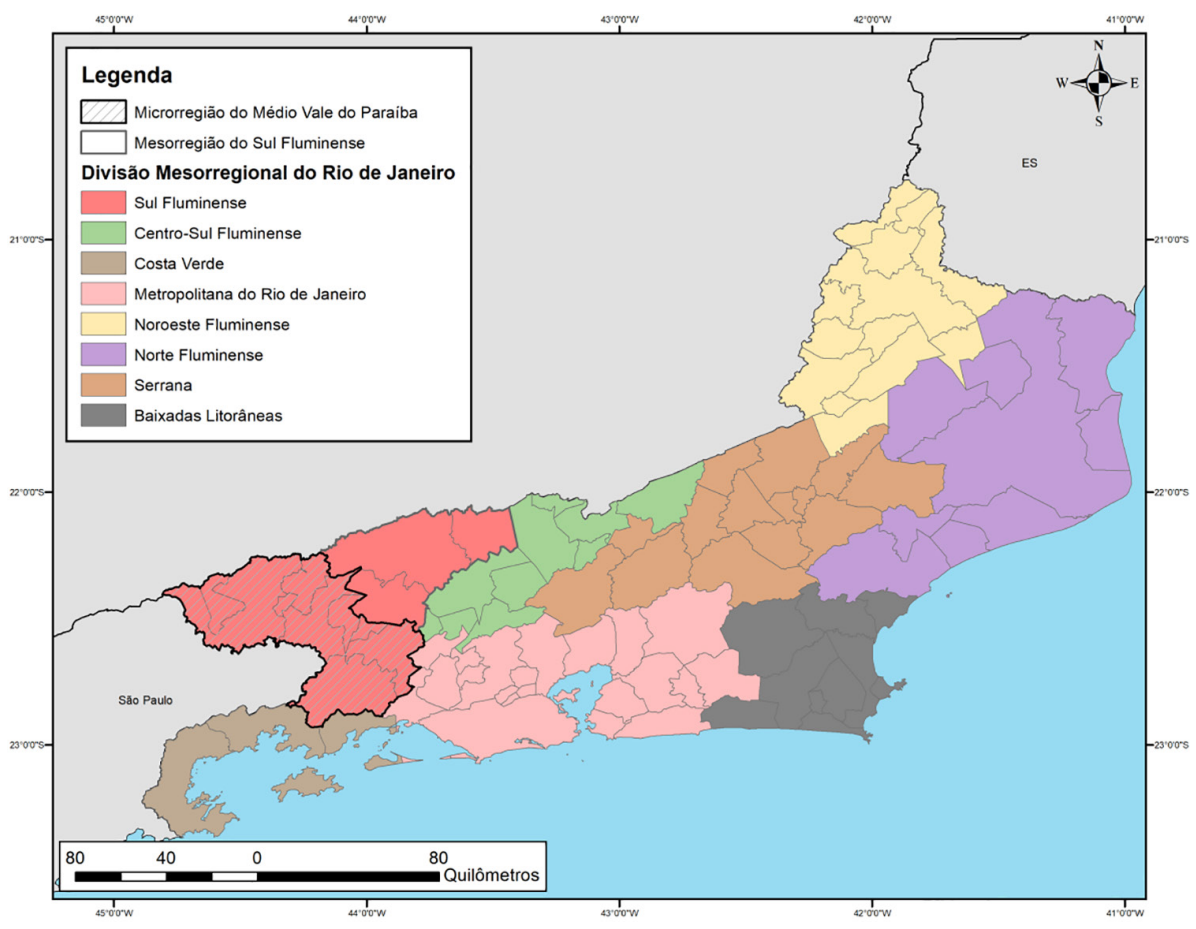

Figura 1 - Localização da mesorregião do sul fluminense e microrregião do Médio Vale do Paraíba.

Fonte: IBGE, 2010.

O motivo de essa região de governo do Estado do Rio de Janeiro comportar tais empresas baseia-se nos fatores já apontados como prestigiados pelo regime de acumulação flexível. Dentre eles, estão: a localização privilegiada da microrregião, posicionada entre os dois principais centros econômicos do Brasil - Rio de Janeiro e São Paulo -; sua boa localização logística, dada uma importante estrutura rodoviária, ferroviária e portuária, sendo esta última representada pelos portos de Santos/SP, de Itaguaí/RJ, de Angra dos Reis/RJ e do Rio de Janeiro/RJ; fácil acesso à Estação Aduaneira Interior (Eadi), que ajuda desde a aquisição de material até o escoamento da produção na microrregião (Figura 2). 


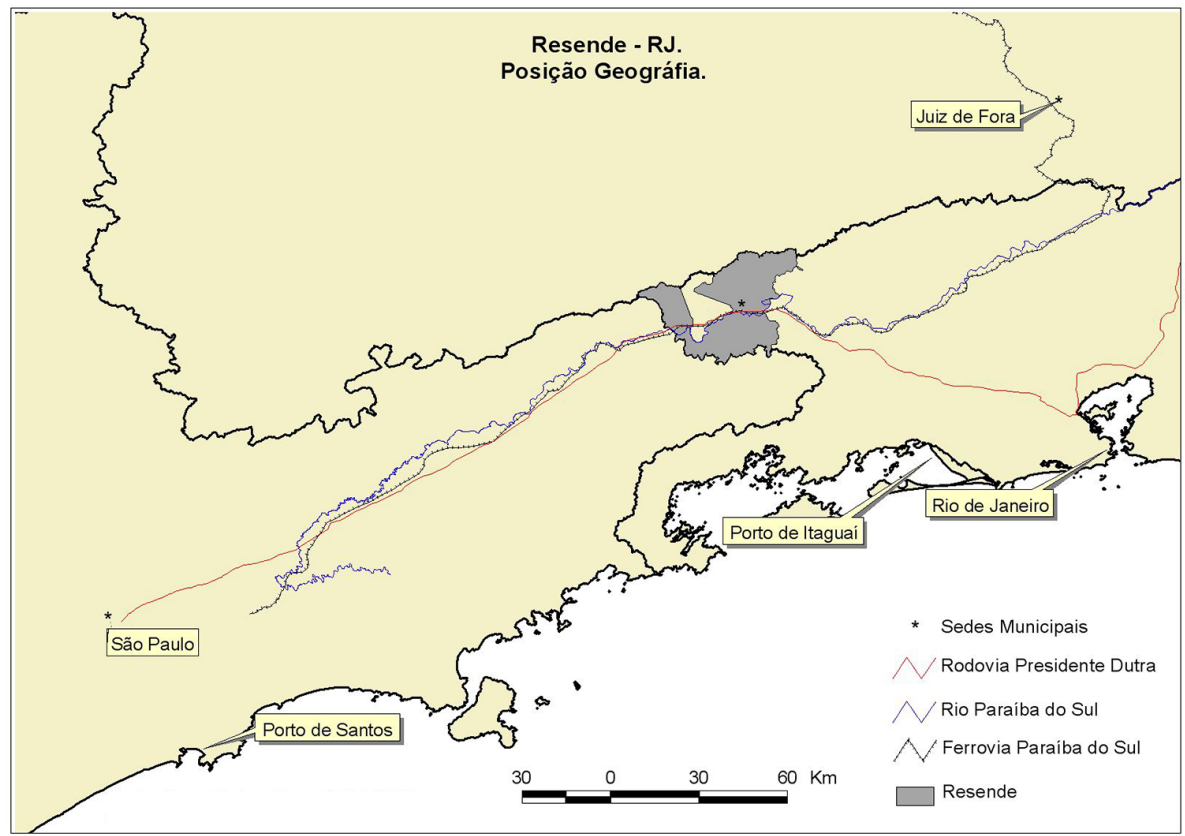

Figura 2 - Resende/RJ - Posição em relação à sua estrutura logística.

Elaborado por: Gabrielle Magalhães, 2011. Fonte: Base Cartográfica, IBGE, 2000.

Além dessas vantagens, outras também justificaram a transformação do Médio Vale do Paraíba em um importante polo industrial brasileiro, sendo elas: a boa oferta de estrutura em comunicação e energia; a disponibilidade de terrenos a preços baixos; isenção fiscal e concessão de facilidades na aquisição de empréstimos; incentivos dados ao estabelecimento de instituições de ensino, com o fim de qualificar a mão de obra local (RAMOS, 2005).

Dessa forma, a despeito de tal descrição, vale acrescentar que essa microrregião não atende sozinha, enquanto totalidade, a tal qualificação; ao contrário, são as suas partes, as cidades médias que a compõem, as maiores protagonistas que explicam o valor produtivo do Sul Fluminense. Nessa direção, para além da dimensão demográfico-quantitativa, as cidades médias precisam ser consideradas também por uma ótica qualitativa, que requer uma análise em um âmbito mais complexo. É como aponta Sposito (2001, p. 627-628) quando diz que:

[...] não é possível reconhecer o papel intermediário que uma cidade média desempenha sem avaliar as relações que ela estabelece com cidades de porte maior e menor, entre si e com os espaços rurais com os quais mantém uma vida de relações. 
Além disso, algumas cidades médias têm sugerido uma reflexão ainda mais profunda na medida em que servem ao processo de desconcentração industrial, a partir do qual algumas atividades produtivas passam a ser operadas de modo mais rentável em espaços diferentes dos grandes centros urbanos. Em outras palavras:

As cidades médias têm sido escolhidas como pontos de apoio de diferentes tipos de empresas, sejam de ramos industriais ou de ramos comerciais, em suas políticas de desconcentração das atividades produtivas e de expansão das redes de comercialização de bens e serviços. (SPOSITO, 2007, p. 11).

Nesse sentido, tal como destaca Stamm (2003, apud STAMM; WADR; STADUTO, 2010, p. 71), "devido às facilidades dos meios de comunicação e transporte, as empresas estão-se interiorizando", buscando, principalmente, "a isenção de impostos e acesso à mão de obra qualificada e, de preferência, não ligada às forças sindicais", o que passa a justificar o incremento de importância adquirida por algumas cidades médias brasileiras, como é o caso de Resende/RJ.

Por isso, a complexidade produtiva da microrregião do Médio Vale do Paraíba Fluminense explica a necessidade de classificação da área a partir de categorias econômicas, que ajudem na descrição de sua natureza produtiva. É o que propõe Limonad (2001) quando apresenta dois eixos que orientam as atividades desempenhadas por essa microrregião, sendo um do segmento de siderurgia, metalurgia, química e construção civil; outro do setor metal-mecânico e da química fina. A partir desse tipo de descrição e classificação, o município de Resende/RJ se encaixa no segundo eixo, este representado por importantes empresas multinacionais estabelecidas ali a partir da década de 1990.

Como exemplo, temos o caso da Volkswagen, que pode ser considerado um marco de um novo momento produtivo experimentado pela cidade média. Fixada no ano de 1996, a empresa foi a primeira indústria automobilística a se instalar em Resende/RJ, sendo seguida pela Nissan, em 2013, além de diversas outras empresas que passaram, durante esse período, a participar da estrutura produtiva da cidade, inclusive de modo complementar ${ }^{1}$.

É a partir de tudo isso que o trabalho pretende compreender os rebatimentos espaciais decorridos na cidade em consequência da alteração de sua dinâmica produtiva. Entendido como o vetor de novos fluxos econômicos, esse processo tem promovido as várias transformações urbanas experimentadas pela cidade média, inclusive a possível produção do seu primeiro subcentro, localizado na via de um dos seus mais importantes bairros, o Cidade Alegria (Figura 3). 
Análise de uma Cidade Policêntrica: o Caso de Resende (RJ), no Médio Vale do Paraíba

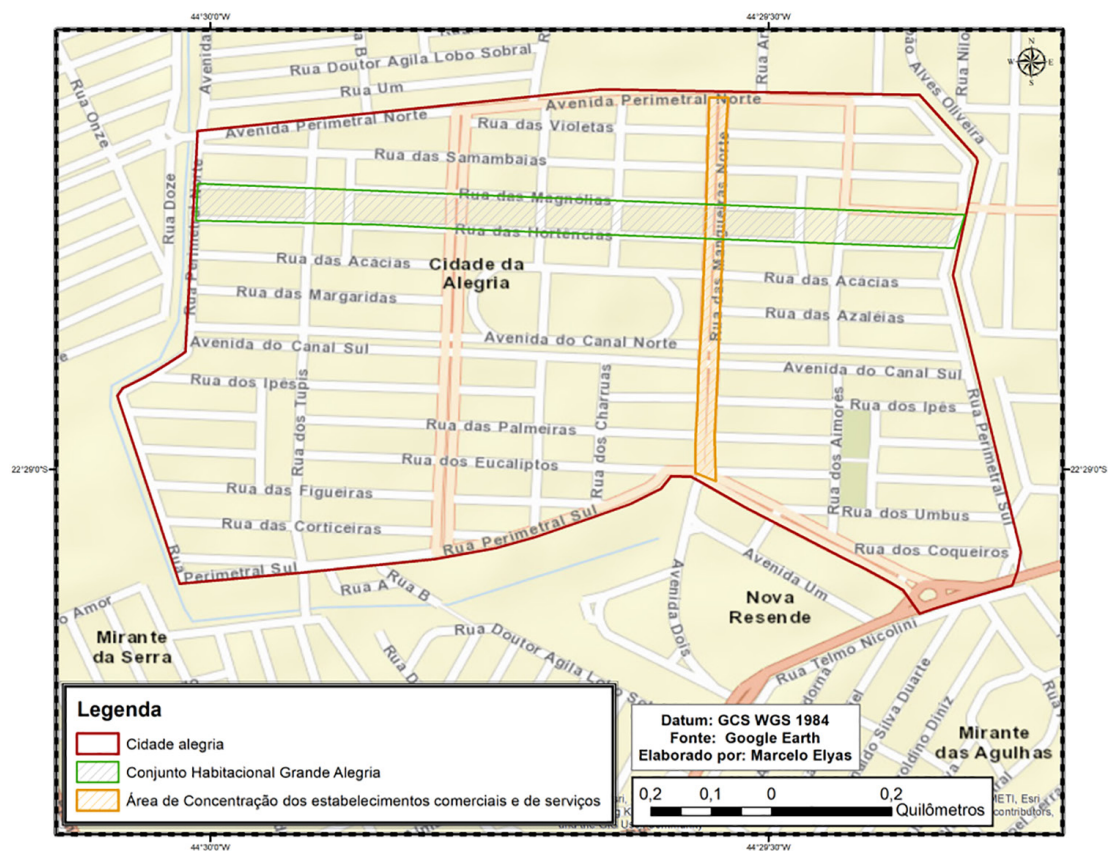

Figura 3 - Resende/RJ - Limites do bairro Cidade Alegria; posição do possível subcentro no bairro e do Conjunto Habitacional Grande Alegria.

Fonte: Google Earth (2015).

Criado na década de 1980, este bairro surgiu como consequência da demarcação do perímetro urbano do município, motivado pela construção de uma estrutura residencial de grande porte no local. O Conjunto Habitacional "Grande Alegria", cujo nome faz alusão à denominação do próprio bairro, é composto até os dias de hoje de 40 blocos - com 32

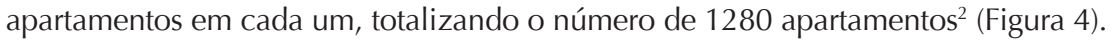

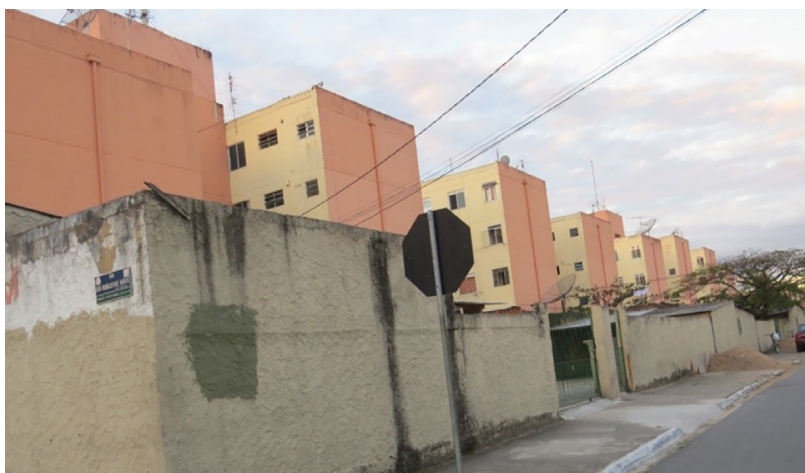

Figura 4 - Resende/RJ - Conjunto Habitacional Grande Alegria, no bairro Cidade Alegria (2013). Foto: Bruno Barreto, trabalho de campo, 2013. 
Concentrando 10\% da população total do município, que é de 119.769 habitantes (IBGE, 2010), foi observado que, na "época da sua construção, o bairro era considerado remoto por dois motivos: a distância do Centro, cerca de $7 \mathrm{~km}$, e a falta de infraestrutura de comércio, serviços, transporte, saúde" (SOUZA, 2011, p. 4) (Figura 5). Porém, nos últimos anos, ele testemunha um adensamento em suas atividades econômicas, sugerindo o que temos apresentado como hipótese: a produção da forma espacial de um subcentro e a tendência da policentralidade urbana.

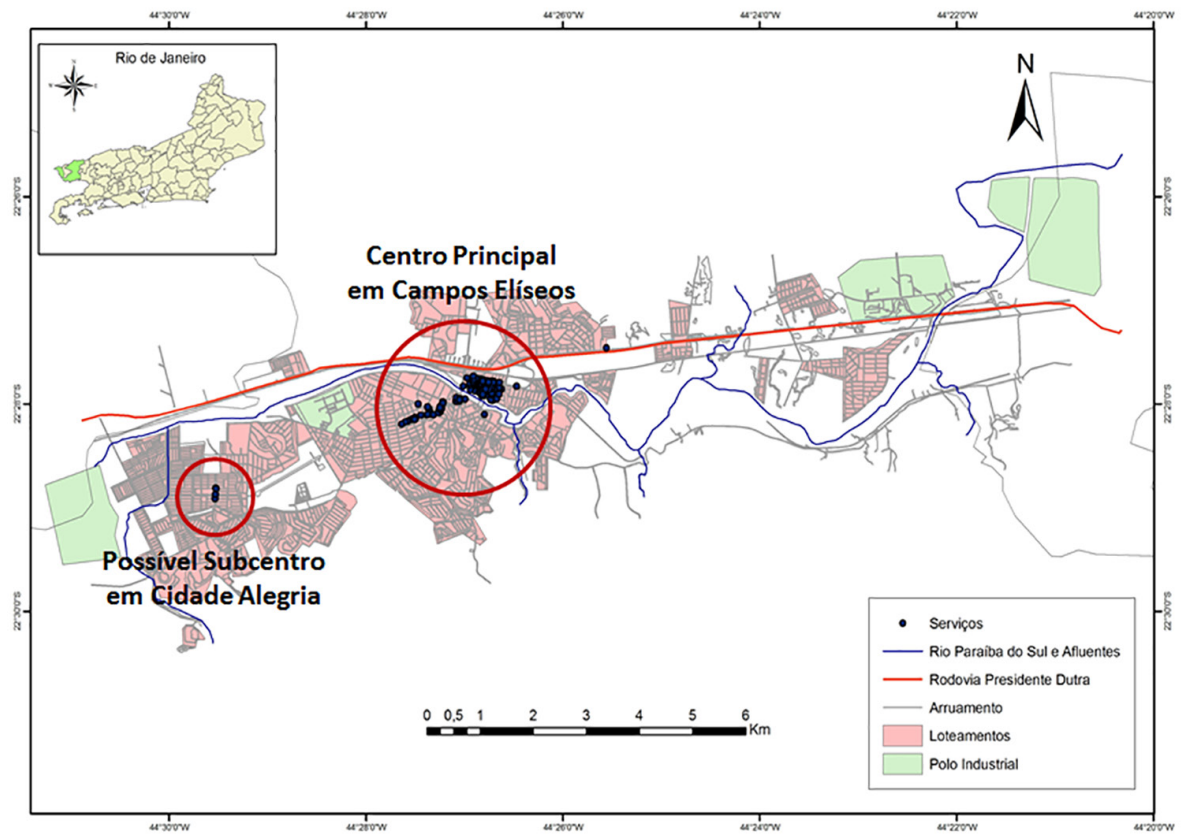

Figura 5 - Resende/RJ - Mapeamento de atividades econômicas.

Elaborado por: Gabrielle Magalhães, 2011. Fonte: Pesquisa de campo, 2009.

Assim, o interesse deste capítulo foi o de não só localizar o objeto de estudo aqui trabalhado, mas também, a partir de sua descrição espacial, situá-lo empiricamente no campo de discussão teórica já construída. Em outras palavras, tanto a posição estratégica de Resende/RJ do ponto de vista econômico-produtivo quanto a localização do bairro Cidade Alegria e a história do seu processo de formação, quando sobrepostos aos conceitos já discutidos, justificam a análise que segue, que se propõe a servir de modelo para a operacionalização de debates sobre reestruturação econômica e urbana no recorte espacial das cidades médias brasileiras. 


\section{Dos Instrumentos de Operacionalização da Pesquisa}

Para que a possibilidade aqui levantada pudesse ser confirmada, foram selecionados elementos metodológicos que respondessem à problemática da ocorrência ou não do processo espacial de descentralização em Resende/RJ. Sendo assim, foi imprescindível a realização imediata de trabalho de campo à época, em agosto de 2013, o qual viabilizaria um contato inicial com a área de estudo, além da execução de metodologia que desse conta da elaboração de respostas à problemática levantada.

Nesse sentido, foi possível perceber que, dentro dos limites do bairro, a concentração de estabelecimentos comerciais e de serviços se dava em um eixo específico do Cidade Alegria. Localizado na Avenida das Mangueiras Sul e continuado na Avenida das Mangueiras Norte, ele fica transversal ao Conjunto Grande Alegria e possuía um número considerável de estabelecimentos. Por isso, o levantamento de atividades econômicas foi de primeira importância para aferir a quantidade desses fixos comerciais e de serviços, que, posteriormente, foram organizados e adequados à Classificação Nacional das Atividades Econômicas (CNAE) proposta pelo Instituto Brasileiro de Geografia e Estatística (IBGE), permitindo uma melhor visualização do perfil comercial da área de estudo.

A utilização de questionários para que o perfil dos frequentadores daquele ponto do bairro pudesse ser avaliado também foi de extrema importância, tendo sido as seguintes questões avaliadas: a origem dos frequentadores; o meio de transporte utilizado para se chegar àquela área; o nível de prioridade dada ao bairro na busca por produtos e serviços; o motivo dessa prioridade; se eles preferiam ou não o frequentarem e por que - dentre outras questões que funcionariam como indicadores da importância econômica daquele possível subcentro para o bairro e seu entorno ${ }^{3}$.

Além desses recursos, o uso de fontes secundárias de dados também foi de extrema importância metodológica, bem como a consulta a outros trabalhos que tinham o recorte do Médio Vale do Paraíba como objeto de estudo. O uso de mapas também foi imprescindível como meio de visualização e melhor compreensão da área estudada, somando-se a todos os demais elementos que ajudaram a compor metodologicamente o desenvolvimento deste trabalho.

\section{O Novo e Primeiro Subcentro de Resende/RJ}

Como já antecipado, a tabulação, organização e análise dos dados foram muito reveladoras da estrutura econômica de parte do bairro Cidade Alegria e da expressão de centralidade irradiada a partir dele. Começando pelo levantamento de atividades econômicas realizado, foi possível quantificar e classificar ${ }^{4}$ a estrutura comercial e dos serviços estabelecidos no bairro, como pode ser visualizado na Tabela 1. 
Tabela 1 - Resende/RJ - Levantamento de Atividades

Econômicas do Bairro Cidade Alegria (2013).

\begin{tabular}{l|c}
\hline \multicolumn{1}{c|}{ Atividades } & Percentual \\
\hline Comércio, reparação de veículos automotores e motocicletas & $53 \%$ \\
\hline Alojamento e alimentação & $21 \%$ \\
\hline Outras atividades de serviços & $17 \%$ \\
\hline Saúde humana e serviços sociais & $3 \%$ \\
\hline Educação & $2 \%$ \\
\hline Atividades profissionais, científicas e técnicas & $1 \%$ \\
\hline Informação e comunicação & $1 \%$ \\
\hline Atividades imobiliárias & $1 \%$ \\
\hline Artes, cultura, esporte e recreação & $1 \%$ \\
\hline TOTAL & $\mathbf{1 0 0} \%$ \\
\hline
\end{tabular}

Fonte: Pesquisa de campo (2013).

De acordo com o levantamento realizado, foram quantificados um total de 139 fixos comerciais e de serviços distribuídos em diversas categorias econômicas, como está apresentado acima. A partir do quadro, é possível perceber uma variedade econômica considerável na estrutura daquele possível subcentro, sobretudo por tratar-se de uma centralidade ainda incipiente. Contudo, além da importância quantitativa dessas informações, é necessário destacar o gênero de alguns dos estabelecimentos encontrados ali, que revelam, inclusive, a participação da iniciativa pública e de outros agentes no reforço da centralidade ali analisada.

Desse modo, merecem destaque a fixação de uma UPA 24hs na área do possível subcentro; uma Farmácia Popular; uma concessionária Honda Motos; dois caixas eletrônicos, do Itaú e Banco do Brasil; uma academia de ginástica, filial de uma unidade estabelecida no Centro Principal de Campos Elíseos; uma unidade da Polícia Militar; uma quadra poliesportiva, de administração municipal; e um supermercado, com 14 caixas e amplo estacionamento de carros e bicicletas ${ }^{5}$.

A reflexão sobre o levantamento dessas atividades naquela área foi bastante reveladora. Além da diversidade econômica, quantidade de estabelecimentos e importância da natureza de alguns deles, a análise indica, também, o importante papel de investimentos públicos no aparelhamento daquela área, com equipamentos urbanos de serviços sendo propulsores da centralidade no bairro. Além disso, é possível identificar a função de outros agentes no processo de descentralização estudado - como é o caso das instituições bancárias ali localizadas -, bem como perceber o interessante caso da academia de ginástica, filial de uma unidade já estabelecida no Centro Principal, o que reforça a possibilidade da ocorrência de descentralização ${ }^{6}$. 
Por outro lado, mas ainda reforçando a hipótese sugerida no decorrer de todo este trabalho, o levantamento dessas atividades permitiu que fosse identificado o perfil do subcentro em análise. Isso porque, como já foi aqui apontado, Silva (2004) indica que a grande maioria dos fixos estabelecidos em um subcentro possui a função de suprimento de demandas locais, pouco heterogêneas, o que pôde ser percebido na estrutura de comércios e serviços no bairro Cidade Alegria. Embora seja possível identificar o início do que pode ser um movimento de diversificação da oferta de bens e serviços dali, em geral e de forma imediata, estes ainda correspondem a uma categoria de consumo mais popular.

Prosseguindo na descrição dos resultados, as informações obtidas a partir dos questionários, além de ajudarem a analisar a ocorrência do processo de descentralização na cidade de Resende/RJ, também contribuem na mensuração da centralidade irradiada do, até então, possível subcentro estudado (Tabela 2).

Tabela 2 - Resende/RJ - Bairro de Origem dos Frequentadores do Subcentro no Bairro Cidade Alegria (2013).

\begin{tabular}{l|c}
\multicolumn{1}{c|}{ Bairro de origem } & Frequentadores \\
\hline Cidade Alegria & $64 \%$ \\
\hline Outros & $36 \%$ \\
\hline TOTAL & $\mathbf{1 0 0} \%$ \\
\hline
\end{tabular}

Fonte: Pesquisa de campo (2013).

Por essas informações, é possível verificar a extensão do alcance espacial da sua centralidade, uma vez que as respostas dos seus frequentadores apontaram para um uso de seus fixos comerciais e de serviços que extrapolaram os limites do próprio bairro, chegando a irradiar para outros do seu entorno. Tal constatação indica o percentual de frequentadores que se deslocam de fora do bairro, de suas respectivas origens, em direção ao possível subcentro.

Por outro lado, com a finalidade de avaliar o nível de preferência dos seus frequentadores, o questionário indagava também a respeito da prioridade dada por eles ao possível subcentro analisado, bem como o motivo desta preferência.

Assim, como pode ser visto no Tabela 3, manteve-se um equilíbrio no padrão de respostas sobre a preferência dada - ou não - à área do possível subcentro no bairro Cidade Alegria, o que não enfraquece a hipótese de ocorrência do processo de descentralização urbana na cidade de Resende/RJ, já que, segundo Reis (2007, p. 11), o surgimento de vários núcleos secundários não colocam em xeque o papel dominante da centralidade mais importante da cidade. Por outro lado, com relação ao motivo da prioridade dada àquela centralidade no bairro Cidade Alegria, a localização foi a opção mais apontada (Tabela 4), o que remonta às razões conjunturais do processo de descentralização - no caso, a distância em relação aos locais de residência quando comparada à do Centro Principal da cidade em questão. 
Tabela 3 - Resende/RJ - Prioridade Dada pelos Frequentadores ao Subcentro no Bairro Cidade Alegria (2013).

\begin{tabular}{l|c}
\hline \multicolumn{1}{c|}{ Prioridade } & Frequentadores \\
\hline Sim & $52 \%$ \\
\hline Não & $48 \%$ \\
\hline TOTAL & $\mathbf{1 0 0} \%$ \\
\hline
\end{tabular}

Fonte: Pesquisa de campo (2013).

Tabela 4 - Resende/RJ - Motivo da Prioridade Dada pelos Frequentadores ao Subcentro no Bairro Cidade Alegria (2013).

\begin{tabular}{l|c}
\hline \multicolumn{1}{c|}{ Motivo da prioridade } & Frequentadores \\
\hline Localização & $65 \%$ \\
\hline Outros & $16 \%$ \\
\hline Preços & $10 \%$ \\
\hline Variedade & $6 \%$ \\
\hline Infraestrutura & $3 \%$ \\
\hline TOTAL & $\mathbf{1 0 0} \%$ \\
\hline
\end{tabular}

Fonte: Pesquisa de campo (2013).

\section{Conclusão}

Portanto, depois de todo o debate conceitual apresentado, da descrição empírica do objeto desta análise e dos resultados revelados, é possível elaborar uma conclusão analítica sobre a hipótese deste trabalho. Como previsível de ser interpretado, é possível inferir sobre a ocorrência do processo espacial de descentralização ocorrido na cidade de Resende/RJ e a produção da forma espacial de seu primeiro subcentro, localizado no bairro Cidade Alegria. Em outras palavras, a dinâmica de reestruturação da cidade média, tão clara do ponto de vista empírico, pôde ser aqui substanciada pela via do processo urbano de descentralização urbana.

Por outro lado, é importante não negligenciar vetores adicionais que têm promovido uma reorganização do espaço urbano da cidade média, sendo a produção do subcentro no bairro Cidade Alegria apenas um deles. Podemos citar o reordenamento imobiliário, com a construção de condomínios fechados de elevado padrão; o adensamento do setor comercial, com o incremento da variedade e quantidade de franquias; e a construção de um shopping center, oferecendo um novo tipo de consumo à cidade. Todos são exemplos de processos que, ao lado do verificado neste trabalho, também têm alterado a estrutura urbana da cidade média. 
Toda essa dinâmica, como já pôde ser apontado, é entendida como influência da reestruturação econômica experimentada por Resende/RJ, tendo em vista o exercício de sua nova função produtiva iniciada na década de 1990. Em outras palavras, assim como diversas pesquisas da mesma natureza, este trabalho surgiu a partir do interesse pela investigação da reestruturação econômica e de sua relação com a reestruturação das cidades, tendo o objetivo de oferecer uma possibilidade de análise para estudos com estes fins. Sendo assim, o trabalho se justificou tanto pela atestação da hipótese inicialmente levantada - da produção do primeiro subcentro de Resende/RJ - quanto pela necessidade de que sejam deslocados esforços acadêmicos para debater cada vez mais o papel das cidades médias na reprodução da lógica produtiva vigente e, por sua vez, para demonstrar as alterações urbanas que tal dinâmica tem promovido nesses mesmos espaços.

\section{Referências Bibliográficas}

CARVALHO, U.M. Reestruturação econômica e urbana no Estado de São Paulo: o papel de Mogi Guaçu e Mogi Mirim na complexa rede urbana paulista. Dissertação em Geografia. Instituto de Geografia, 2013, Universidade Federal do Rio Grande do Sul, Porto Alegre.

COLBY, C. Centrifugal and centripetal forces in urban geography. Annals of the Association of American Geographers. v. 23, n. 1, p. 1-20, 1933.

CORRÊA, R.L. O espaço urbano. 4. ed. São Paulo: Ática, 1989.

HARVEY, D. A condição pós-moderna. 16. ed. São Paulo: Loyola, 2007.

LENCIONI, S. Reestruturação: uma noção fundamental para o estudo das transformações e dinâmicas metropolitanas. In: VI Encontro de Geógrafos da América Latina. Anais. Buenos Aires, Universidade de Buenos Aires, 1998b. p.1-10.

MOREIRA, R. Reestruturação industrial e espacial do Estado do Rio de Janeiro. Niterói: Geret/Neret Negt Gecel, 2003.

LÉFÈBVRE, H. O conceito de Estrutura em Marx. In: BASTIDE, R. (org.). Usos e sentidos do termo "estrutura", São Paulo: Edusp/Herder, 1971. p. 101-107.

LIMONAD, E. Relatório anual CNPq 2001. Referente aos dois primeiros anos da pesquisa "Reestruturação produtiva, redes empresariais e dinâmicas locais e regionais no Sul Fluminense" - Projeto integrado ao CNPq no período de 1999-2002 (2001).

RAMOS, T. T. Reestruturação produtiva e des-territorialização no Médio Vale do Paraíba Fluminense. Dissertação em Geografia. Instituto de Geografia, 2005, Universidade Federal Fluminense, Rio de Janeiro.

SANTOS, M. Espaço e método. São Paulo: Nobel, 1985. 
SILVA, W. R. Centralidade, shopping centers e reestruturação das cidades médias. In: MAIA, D.S.; SILVA, W.R.; WITHACKER, A.M. (org.). Centro e centralidade em cidades médias. São Paulo: Unesp - Cultura Acadêmica, 2017a. v. 1. p. 199-226.

Shopping centers e a redefinição da centralidade em cidades médias brasileiras. In: MAIA, D. S.; SILVA, W. R.; WITHACKER, A. M. (org.). Centro e centralidade em cidades médias. São Paulo: Unesp - Cultura Acadêmica, 2017b. v. 1. p. 227-285.

Novos centros, novas centralidades, novas diferenças. A fragmentação do espaço urbano de Londrina. Geografia, 2004, n. 1, 2004. v. 29. p. 55-70.

SPOSITO, E. S. Reestruturação produtiva e reestruturação urbana no Estado de São Paulo. In: IX Colóquio Internacional de Geocrítica: Los Problemas del Mundo Actual. Soluciones y Alternativas desde la Geografía y las Ciencias Sociales, Porto Alegre. Anais..., Universidade do Rio Grande do Sul, 2007.

SPOSITO, M. E. B. ; SILVA, W. R. Um tema, um livro, um debate? Reestruturações e cidades médias. In: SILVA, W. R.; SPOSITO, M. E. B. (orgs.). Perspectivas da urbanização. Reestruturação urbana e das cidades. Rio de Janeiro: Consequência, 2017. v. 1.p. 9-31.

As cidades médias e os contextos econômicos contemporâneos. In: SPOSITO, M. E. B. (org.). Urbanização e cidades: perspectivas geográficas. Presidente Prudente: [s.n.], 2001.

. O chão em pedaços: urbanização, economia e cidades no Estado de São Paulo. 504f. Tese (Livre Docência)-Faculdade de Ciências e Tecnologia. Unesp-Campus Presidente Prudente. Presidente Prudente, 2004.

Reestruturação Urbana e Segregação Socioespacial no Interior Paulista. In: IX Colóquio Internacional de Geocrítica: Los Problemas del Mundo Actual. Soluciones y Alternativas desde la Geografía y las Ciencias Sociales, Porto Alegre. Anais..., Universidade do Rio Grande do Sul, 2007.

SOJA, E.W. Geografias pós-modernas - a reafirmação do espaço na teoria social crítica. Rio de Janeiro: Jorge Zahar, 1993.

SOUZA, R.G. A construção do bairro popular Cidade Alegria na cidade de Resende-RJ, segundo a lógica de reestruturação produtiva. Rio de Janeiro, 2011. Trabalho de Conclusão de Curso (Graduação em Geografia) Instituto de Geografia, Universidade Federal do Rio de Janeiro, 2011.

STAMM, C. Análise dos fatores que influenciaram a localização das indústrias no Estado do Paraná. Relatório de Pesquisa - PIBIC/CNPq. Universidade Estadual do Oeste do Paraná - Unioeste/Campus de Toledo, 2003. 
; WADI, Y. M.; STADUTO, J. A. R. São as cidades médias responsáveis pelo espraiamento espacial da riqueza nacional? Rede Brasileira de Estudos sobre Cidades Médias - REDBCM REDES, Santa Cruz do Sul, v. 15, n. 2, p. 66-91, 2010.

Recebido em: 1/7/2017 Aceito em: 1/8/2017

\footnotetext{
1 A microrregião do Médio Vale do Paraíba é considerada um polo automotivo por comportar, também, diversas outras indústrias dessa mesma natureza em vários dos seus municípios. Esse é o caso de Porto Real, que recebeu a unidade da Peugeot/Citröen (2001), e de Itatiaia, que comporta as montadoras Hyundai Heavy Industries (2011) e Jaguar Land Rover (2016). Desse modo, levando em conta a proximidade entre tais municípios, limítrofes à Resende/RJ, é impossível compreender os reflexos urbanos dessa dinâmica produtiva de modo compartimentado, limitado ao espaço intraurbano de cada cidade. Assim, é preciso considerar que, tanto as condições, como os rebatimentos espaciais das funções econômicas desempenhadas por cada município são ampliados, por, juntos, formarem uma economia de escala.

2 Informação relativa à estrutura do Conjunto Grande Alegria extraída da monografia intitulada "A construção do bairro popular Cidade Alegria na cidade de Resende (RJ) segundo a lógica de reestruturação produtiva e da cidade", de Souza (2011).

${ }^{3}$ Ambos os recursos, o de levantamento de atividades econômicas e da aplicação dos questionários, foram operados na ocasião de um dos trabalhos de campo realizados em Resende/RJ, tendo sido possível a abordagem de 59 pessoas na área do suposto subcentro da cidade média.

${ }^{4}$ Os resultados obtidos foram padronizados segundo a CNAE-Classificação Nacional de Atividades Econômicas/IBGE -, posteriormente adaptados à realidade da estrutura comercial identificada ali.

${ }^{5}$ Informação relativa ao supermercado extraída da monografia intitulada "A construção do bairro popular Cidade Alegria na cidade de Resende (RJ) segundo a lógica de reestruturação produtiva e da cidade", de Souza (2011).

${ }^{6}$ Segundo Corrêa (1989), o estabelecimento de filiais do Centro Principal em uma possível área de subcentralidade é um forte indicador do processo de descentralização urbana.
} 